\title{
RESUMEN
}

El sistema de facturación, a través del tiempo muestra una conducta evolutiva de cambios constantes, que tienen como fin generar facilidades, para sus beneficiarios. Las reformas tributarias al sistema de facturación, cumplen un papel primordial en el perfeccionamiento del sistema mismo, considerando que la administración tributaria, se ha enfocado de tal manera que las reformas efectuadas, no sean consideradas únicamente como una medida de control, hacia los contribuyentes, sino más bien una herramienta para mejorar y potencializar los sistema de facturación dentro de las entidades económicas, con la finalidad de lograr que su eficiencia y eficacia hagan parte de sus fortalezas empresariales. Basados en el principio de simplicidad administrativa, se busca comprobar que las reformas efectuadas al sistema de facturación cumplen con lo estipulado en el estudiado principio, el mismo que determina la obligatoriedad de la administración tributaria, al brindar al contribuyente, las facilidades necesarias para que cumpla con sus deberes y formalidades tributarias.

Palabras Claves: sistema de facturación, principio de simplicidad administrativa, contribuyente, tributo.

\section{EL PRINCIPIO DE SIMPLICIDAD ADMINISTRATIVA APLICADO A TRAVÉS DEL SISTEMA DE FACTURACIÓN}

\author{
Mauricio Arias Pérez1 / Shirley Ordoñez Pico
}

\author{
Fechas de recepción: 17 de septiembre de 2020 \\ Fecha de aceptación: 20 de octubre de 2020
}

DOI: https://doi.org/10.22370/riace.2020.9.1.2601

1 Corresponding Author. Facultad de Contabilidad y Auditoría, Universidad Técnica de Ambato, Ambato, Ecuador, mauriciogarias@uta.edu.ec

2 Ingeniera en Contabilidad y Auditoría, Ambato, Ecuador, sordonez8476@uta.edu.ec 


\title{
THE PRINCIPLE OF ADMINISTRATIVE SIMPLICITY APPLIED THROUGH BILLING SYSTEM
}

\begin{abstract}
The billing system, over time shows an evolutionary behavior of constant changes, which are aimed at generating facilities for its beneficiaries. Tax reforms to the billing system play a key role in the improvement of the system itself considering that the tax administration has focused in such a way that the reforms carried out are not considered only as a control measure, towards taxpayers, but rather a tool to improve and potentiate the billing system within economic entities, in order to make their efficiency and effectiveness part of their business strengths. Based on the principle of administrative simplicity, it seeks to verify that the reforms made to the billing system comply with the stipulated in the principle studied, which determines the obligation of the tax administration, by providing the taxpayer with the necessary facilities to comply with its tax duties and formalities.
\end{abstract}

Keywords: billing system, administrative simplicity principle, taxpayer, tribute. 


\section{INTRODUCCIÓN}

El sistema de facturación se encuentra inmerso en el mundo desde 1821 donde la historia de España nos relata la aparición de un documento de papel (factura) que tiene como finalidad, respaldar una transacción o intercambio de bienes. Aparece por primera vez en la ciudad de Madrid, y surgió con la finalidad de generar valor, el mismo que ayudó mediante el periodo de constantes guerras, de aquellos tiempos, considerando que las mismas inquietaban el peligro del Estado, es donde nace la idea y se realizan un sin número de reformas útiles, con el fin de que las personas puedan reclamar sus derechos de posesión sobre sus bienes, sustentados en un documento que respalde sus pertenencias. Inicialmente se utilizó este método en haciendas, la idea se dio, con el fin de proteger los bienes llamados nacionales, así como fincas pertenecientes a órdenes religiosas, que eran vendidas por disposición legislativa, y restituidas después por una orden del rey a sus dueños antiguos, sin considerar, la inversión ni las mejoras que se realizaban. Este tipo de conductas arbitrarias generaba dentro de los habitantes, grandes controversias, las mismas que fueron aplicadas con la ayuda de un documento de valor que, les daba derecho sobre sus pertenencias. (Alcalá, 1846)

Mediante la aparición de un documento, se genera el inicio de lo que hoy en día conocemos como sistema de facturación, que no es sino el conjunto de procesos, documentos, y demás transacciones que hacen, que las actividades económicas sean respaldadas, y fruto de esto se genere una conducta de control, sobre empresas y entidades económicas.

El objetivo de este estudio es analizar, la influencia de las reformas tributarias en el sistema de facturación, basados en el principio de simplicidad administrativa. El mismo que tiene como finalidad brindar al contribuyente, todas aquellas facilidades, en procesos administrativos, así como la agilidad y simplicidad a la hora de cumplir con sus obligaciones tributarias, para que de esta manera se genere una colaboración entre la administración tributaria y el contribuyente, con el objeto de generar beneficios entre las partes.

Dentro de este estudio se tomó en consideración las dos variables que son el sistema de facturación, y el principio de simplicidad administrativa, haciendo una relación de dependencia y cumplimiento, para el desarrollo de las actividades económicas de los contribuyentes.

\section{DESARROLLO}

\section{Sistema de facturación a través de la historia}

La facturación como un sistema de datos, se hace presente en la historia desde los remotos sistemas impositivos contemporáneos que se realizaban a través de los censos, efectuados en la Edad Media y en cierta forma han subsistido hasta 
nuestros días con las diferentes modificaciones y transformaciones debido al progreso de la ciencia de las finanzas y de las necesidades económicas de los diferentes estados; la situación tributaria en la edad media, hace notar los orígenes históricos de ciertos gravámenes, tales como los impuestos aduanales, los que gravan el consumo, todos fundamentados en un sistema de facturación tradicional bien estructurado, el mismo que dio paso más adelante al impuesto sobre la renta, cuya aparición se hace datar de 1789 en Inglaterra. (González, 2012)

El origen del primer sistema de facturación fue en Portugal en 1931 mediante un decreto de ley del mismo año, según Romero \& Fajardo (2010) se dio paso a un conjunto de procesos "al regularse el contrato de compra venta, y es como se creó el denominativo de factura, como un documento negociable, válido para cobrar el precio de los bienes vendidos, dándole al usuario un título de valor.” (p.221)

Años más tarde se da a conocer el impuesto al valor agregado y se sostiene que su origen fue en Francia en el año 1948, siendo este país el pionero. En la actualidad este impuesto se encuentra en vigencia en más de 130 países a nivel mundial, generando una recaudación tributaria que consta más de una cuarta parte, para cada uno de los países quienes se han acogido a este tributo. (Bustos, 2007)

Dentro de un sistema de facturación ya sea tradicional, digital o electrónico, el documento soporte es la factura la misma que se considera como el justificante fiscal de la entrega de un producto o de la provisión de un servicio, que afecta al obligado tributario emisor comúnmente conocido como el vendedor y al obligado tributario receptor quien es el comprador. La factura a lo largo del tiempo se consideró como el único justificante fiscal, que da al receptor el derecho de deducción del impuesto IVA, cosa que no sucede con ningún otro documento sustituto. (Revelles, 2017)

La administración tributaria a nivel de América Latina ha sobrellevado un sin número de dificultades, puesto que en su mayoría los sectores tienden por su naturaleza a ser difícilmente controlables. Es donde actúan los organismos de control, esencialmente la administración tributaria como ente regulador, que busca dinamizar, y simplificar los procesos para el sistema de facturación con el objetivo de mejorar el control sobre los contribuyentes, al manejar un registro de transacciones digitales o electrónicas, se crea un ambiente organizado donde los beneficios se ven reflejados en las partes interesadas.

En la década de los 70, se consideraba como un desafío la aplicación de un sistema eficiente que controle la facturación en mercados informales, y la evasión del impuesto al valor agregado, a los principales regímenes simplificados estuvieron dirigidos a sustituir exclusivamente este impuesto. Si bien se utilizaron variadas técnicas presuntivas, la que tuvo mayor aplicación en la subregión fue la técnica del "débito fiscal presunto y crédito fiscal real". (González, 2006)

Entre algunos de los países pioneros en adoptar un sistema de facturación tradicional, se toma en consideración a Chile, México y Colombia, los mismos 
que al pasar los años y los múltiples avances de la tecnología mejoraron e incrementaron un sistema de facturación electrónica siendo hoy en día la tendencia y la opción factible para todos los sujetos pasivos, con el fin de llevar un control tributario eficiente.

En la línea de tiempo del que hacer tributario en el Ecuador, en el año 1997 se identifica una gran división entre dos periodos completamente distintos. Con anterioridad al año indicado, la sociedad ecuatoriana en su conjunto tenía una respuesta muy pobre frente a la contribución fiscal. Este hecho, se sustentaba en el limitado trabajo en políticas fiscales y la ausencia de una Administración Tributaria. (Barberán \& Unapanta, 2016)

Con los inicios de los gobiernos constitucionales en el Ecuador, surge una idea de democracia y control, con el fin de tener una garantía sobre el desarrollo de la economía, según (Barberán \& Unapanta, 2016) fue indispensable, la necesidad de obtener recursos corrientes, mediante impuestos, para tener un presupuesto balanceado, esta fue la idea primordial en la implementación y evolución de un sistema tributario, cuya influencia ha sido cada vez más significativa en la vida cotidiana de la población ecuatoriana, al igual que en las decisiones empresariales. Aunque uno de los preceptos para la creación del Servicio de Rentas Internas fue el desarrollo de una "cultura tributaria", en la práctica la Administración Tributaria es solo uno de los actores en las relaciones del Estado con los contribuyentes.

Una vez establecida la administración tributaria en el país, se busca fusionar tanto las normas tributarias con las constitucionales, para que de esta manera exista un ente de control eficaz y eficiente, donde los contribuyentes son el objetivo primordial frente a cualquier decisión.

En la resolución el Servicio de Rentas Internas (2015) indica e informa "que es deber de la administración tributaria, expedir las normas necesarias para facilitar a los contribuyentes el cumplimiento de sus obligaciones tributarias y deberes formales." "El principio constitucional, de eficiencia implica una racionalización a favor de la incorporación tecnológica, simplificación en pro de la sencillez, eficiencia y economía de trámites y modernización para fortalecer los nuevos cometidos estatales, y la simplicidad administrativa."

A continuación, se presenta en la Tabla 1 la evolución del sistema de facturación en el Ecuador desde sus inicios hasta la presente fecha 


\begin{tabular}{|c|c|}
\hline AÑ̃ & DETALLE \\
\hline 1970 & La facturación en conjunto con el impuesto al valor agregado fue adoptada en Ecuador \\
\hline 1997 & $\begin{array}{l}\text { Se creó el Servicio de Rentas Internas como organismo encargado de efectuar la } \\
\text { determinación, recaudación y cobro de los tributos internos }\end{array}$ \\
\hline 1999 & $\begin{array}{l}\text { Mediante decreto No. } 1011 \text { Jamil Mahuad presidente constitucional de la república, } \\
\text { decreta el REGLAMENTO DE FACTURACIÓN, con el fin de expedir las normas } \\
\text { reglamentarias para la aplicación de la Ley para la Reforma de las Finanzas Públicas. }\end{array}$ \\
\hline 2002 & $\begin{array}{l}\text { Mediante Decreto Ejecutivo No. 3055, registro oficial No. } 679 \text { se expidió el } \\
\text { REGLAMENTO DE COMPROBANTES DE VENTA Y RETENCIÓN } \\
\text { Decreto del reglamento y la Ley de Comercio Electrónico, Firmas Electrónicas y } \\
\text { Mensajes de Datos de } 17 \text { de abril de } 2002 \text { regula los mensajes de datos, la firma } \\
\text { electrónica, los servicios de certificación, la contratación electrónica y telemática, } \\
\text { la prestación de servicios electrónicos a través de redes de información, incluido el } \\
\text { comercio electrónico y la protección a los usuarios de estos sistemas. }\end{array}$ \\
\hline 2009 & $\begin{array}{l}\text { La Secretaría Nacional de la Administración Pública establece que se encuentran tres } \\
\text { empresas autorizadas para la emisión de comprobantes electrónicos. }\end{array}$ \\
\hline 2010 & $\begin{array}{l}\text { Mediante decreto } 430 \text {, registro oficial } 247 \text { se expidió el REGLAMENTO DE } \\
\text { COMPROBANTES DE VENTA, RETENCIÓN Y DOCUMENTOS COMPLEMENTARIOS. }\end{array}$ \\
\hline 2012 & $\begin{array}{l}\text { El Servicio de Rentas Internas empezó un proceso de implementación normativa y } \\
\text { tecnológica para brindar en línea los servicios de certificación, validación, autorización, } \\
\text { y almacenamiento mediante RESOLUCIÓN N N NACDGERCGC12-00105 (Anexo 2) } \\
\text { donde se expide las normas para el nuevo esquema de emisión de comprobantes de } \\
\text { venta. Art. } 2 \text { prevé que los sujetos pasivos de tributos podrán emitir como mensajes } \\
\text { de datos conforme la definición de la Ley de Comercio Electrónico. }\end{array}$ \\
\hline 2013 & $\begin{array}{l}\text { Desde el } 6 \text { de mayo de } 2013 \text { a raíz de la RESOLUCIÓN NAC-DGERCGC13-00236, } \\
\text { la factura electrónica empezó a ser obligatoria en Ecuador para aquellos sectores } \\
\text { económicos seleccionados por el Servicio de Rentas Internas y de manera voluntaria } \\
\text { para aquellos que deseaban acogerse al sistema. }\end{array}$ \\
\hline 2014 & $\begin{array}{l}\text { Mediante resolución No. NAC-DGERCGC14-00790, publicada en el tercer Suplemento } \\
\text { del registro oficial No. } 346 \text { en su núm. } 6 \text { art. } 3 \text { manda que, para la emisión de } \\
\text { comprobantes electrónicos, de manera obligatoria para, los sujetos pasivos deberán } \\
\text { estar a lo dispuesto en la "ficha técnica", así como los requisitos adicionales de unidad } \\
\text { y demás especificaciones detalladas en los archivos XML y XSD que el Servicio de } \\
\text { Rentas Internas publique en su página institucional. }\end{array}$ \\
\hline 2015 & $\begin{array}{l}\text { A través de RESOLUCIÓN NAC-DGECCGC15-00000007 de } 04 \text { de mayo de } 2015 \\
\text { hace referencia a los sujetos pasivos emisores de comprobantes electrónicos en } \\
\text { referencia a: oportunidad de la entrega y notificación del comprobante electrónico al } \\
\text { receptor, emisión a consumidores finales, oportunidad de entrega del comprobante } \\
\text { de retención y anulación de comprobantes electrónicos. } \\
\text { RESOLUCIÓN NAC-DGERCGC15-0000004 de } 12 \text { de enero de } 2015 \text { establece la } \\
\text { obligatoriedad de emisión de comprobantes electrónicos para notarios. }\end{array}$ \\
\hline 2016 & $\begin{array}{l}\text { Se agrega el requisito en los comprobantes de venta utilizados por los sujetos pasivos } \\
\text { que transfieran bienes o prestan servicios públicos con subsidios. }\end{array}$ \\
\hline 2017 & $\begin{array}{l}\text { Se establecen regulaciones al sistema de facturación para el cumplimiento de los } \\
\text { deberes formales de los contribuyentes que ejerzan la actividad de transporte terrestre. }\end{array}$ \\
\hline 2018 & $\begin{array}{l}\text { A partir del primero de enero de este año, todas las empresas del país estarán } \\
\text { obligadas a implementar la facturación electrónica como única forma de su registro } \\
\text { contable de transacciones. } \\
\text { Por ello, para dar cumplimiento a la resolución No. NAC-DGERCGC15-00000745-B }\end{array}$ \\
\hline
\end{tabular}

Fuente: Servicio de Rentas Internas (2017)

Sistema de facturación tradicional, digitalizado, y electrónico. 
El sistema de facturación es el "proceso a través del cual se autoriza la emisión de comprobantes de venta, documentos complementarios y comprobantes de retención los mismos que acreditan la transferencia de bienes, la prestación de servicios o la realización de otras transacciones gravadas con tributos." Servicio de Rentas Internas (2017)

El control tributario es de vital importancia en la economía de todos los países por que, mediante un sistema de facturación eficiente, se puede medir el rendimiento y la capacidad económica de los sujetos pasivos, inscritos a un registro único de contribuyentes. Sin el control adecuado de las trasferencias económicas, ya sean de bienes o servicios, no existiría la declaración de tributos adecuada, lo que representa un aporte fundamental para el sustento de la política pública, y consigo la ejecución de obras y demás beneficios que nos corresponden como comunidad, por lo que debemos declarar de manera veraz y legal nuestros ingresos y gastos, contribuyendo con la mejora del país.

Como contribuyentes es importante cumplir con los deberes formales que dictaminan los entes reguladores como es el Servicio de Rentas Internas donde todo contribuyente se compromete de manera voluntaria a llevar registros contables de las actividades económicas y pagar los impuestos que dictamina la ley, en nuestro país se pretende controlar el nivel de compras y ventas mediante un sistema de facturación.

Tabla 2. Tipos de Sistemas de Facturación.

\begin{tabular}{|l|l|l|}
\hline \multicolumn{1}{|c|}{ FASES } & AÑO & \multicolumn{1}{c|}{ DESCRIPCIÓN } \\
\hline $\begin{array}{l}\text { 1.- Facturación } \\
\text { tradicional }\end{array}$ & 1970 & $\begin{array}{l}\text { Ecuador se acogió por primera vez al sistema de facturación tradicional, } \\
\text { o mediante documentos físicos que sustenten actividades tradicionales, } \\
\text { los mismos que surgen de la necesidad de controlar las actividades } \\
\text { económicas, con el fin de saber a ciencia cierta, las ganancias efectuadas } \\
\text { de inversiones. }\end{array}$ \\
\hline $\begin{array}{l}\text { 2.- Digitalización } \\
\text { de información }\end{array}$ & 2000 & $\begin{array}{l}\text { Con la aparición de nuevas y mejoradas tecnologías, se incrementan } \\
\text { a las empresas ecuatorianas los denominados softwares contables, } \\
\text { los mismos que cuentan con módulos de facturación, donde las } \\
\text { transacciones empiezan de manera digital, pero sin olvidar la impresión } \\
\text { de los comprobantes con el fin de tener en constancia física, la ejecución } \\
\text { de transacciones de compra y venta. }\end{array}$ \\
\hline $\begin{array}{l}\text { 3.- Facturación } \\
\text { electrónica }\end{array}$ & 2009 & $\begin{array}{l}\text { A través, del paso del tiempo se considera que la impresión de } \\
\text { comprobantes de venta no solo sustenta un enorme gasto económico, } \\
\text { sino también un daño ambiental, y se busca que con la facturación } \\
\text { electrónica quede en el pasado, el papeleo y archivo físico generados por } \\
\text { la facturación, con el fin de no solo generar un control más exhaustivo } \\
\text { para con los contribuyentes, sino también, contar con un almacenamiento } \\
\text { virtual ilimitado. }\end{array}$ \\
\hline
\end{tabular}




\section{Principio de simplicidad administrativa}

El límite del Poder Tributario del Estado se encuentra estipulado y delimitado dentro de sus principios que tienen como finalidad, que los derechos fundamentales de las personas no sean vulnerados, así también que no se contradiga con los derechos de otros sectores que existan dentro de una misma legislación. (Zambrano, 2010)

Según la constitución del Ecuador (2008) en su sección quinta Art. 300 determina que: "El régimen tributario se regirá por los principios de generalidad, progresividad, eficiencia, simplicidad administrativa, irretroactividad, equidad, transparencia y suficiencia recaudatoria. Se priorizarán los impuestos directos y progresivos."

La simplicidad administrativa, estipula que las estructuras administrativas y sus competencias sean de fácil comprensión y entendimiento, sin procedimientos rebuscados que retarden la satisfacción de los intereses públicos impuestos. Este principio obliga a la administración pública cumplir con sus objetivos y fines de satisfacción, a través de los diversos mecanismos y herramientas, de la forma más explícita, rápida y acertada posible para evitar retardos indebidos. Este conjunto de principios le impone exigencias, responsabilidades y deberes permanentes a todos los entes públicos que no pueden renunciar de forma temporal o singular. (Solano, 2004)

Mediante la constante aplicación de este principio, podemos observar que la administración tributaria, constantemente realiza, la reforma de un sin número de resoluciones, con el fin de facilitar el entendimiento de la normativa y sobre todo que los contribuyentes tengan todas las facilidades para poder cumplir con sus obligaciones tributarias, con el ahorro de recursos y en especial la optimización del tiempo.

Un claro ejemplo de la aplicación del principio de simplicidad administrativa es la digitalización de las declaraciones, de esta manera los contribuyentes no deben comprar formularios y únicamente realizan sus declaraciones en línea.

La finalidad de la implementación total de un sistema de facturación electrónica es el mismo, cumplir con el mencionado principio, no solo se busca el control tributario, si no se ve la necesidad de los contribuyentes de optimizar mediante la emisión de comprobantes electrónicos generando un ahorro sustancial, así también como la disminución de tiempo empleado en la declaración de sus impuestos.

La simplicidad administrativa "no se limita a la tramitología de procedimientos de liquidación y pago de tributos, sino también a olvidar la serie de requerimientos e información que se solicita en reclamos administrativos, y comprende una obligación para el legislador y para los administradores de tributos de simplificar la normativa existente." (Bustos, 2012) 


\section{METODOLOGÍA}

La presente investigación se enmarca en el enfoque cualitativo, donde se da un profundo análisis al sistema de facturación, tomando como relación el principio de simplicidad administrativa que está inmerso en la evolución del sistema estudiado, considerando que cada reforma se ha hecho en base al cumplimiento del principio tributario analizado en la investigación. El estudio se aplicó a un total de 43 empresas entre compañías limitadas y sociedades anónimas denominadas como contribuyentes especiales de la ciudad de Ambato, siendo la mayor parte de estas empresas que se dedican al comercio masivo de productos y con un flujo de ventas altamente elevado. Se aplicó encuestas con 22 preguntas de tipo cerrada y de opción múltiple para conocer aspectos relacionados sobre el sistema de facturación y el principio de simplicidad con relación a su cumplimiento y conocimiento.

\section{RESULTADOS}

La información expuesta por la población estudiada señala que el sistema de facturación en todas sus fases ha dado satisfactorios resultados; sin embargo, su adopción se la realizó de manera obligatoria, con la finalidad de cumplir con los requerimientos de la normativa tributaria. Se considera que el $100 \%$ de la población estudiada utiliza un sistema de facturación, del cual el $81 \%$ posee un sistema de facturación electrónica, cumpliendo de manera eficiente con el proceso de facturación.

Tabla 3. Sistemas de Facturación por Contribuyentes.

\begin{tabular}{|c|c|c|}
\hline ALTERNATIVAS & RESPUESTA & PORCENTAJES \\
\hline Sistema de facturación tradicional & 2 & $5 \%$ \\
\hline Sistema de facturación digitalizada & 6 & $14 \%$ \\
\hline Sistema de facturación electrónica & 34 & $81 \%$ \\
\hline
\end{tabular}

Fuente: contribuyentes especiales de Ambato

En base a los resultados analizados, se comprueba que, con la aplicación del principio de simplicidad administrativa, el sistema de facturación ha generado su objetivo propuesto, los contribuyentes han simplificado sus procesos, han mejorado el control de sus ventas y compras, además la simplicidad con la que se ejecuta el sistema de facturación electrónico hace posible la facilidad de cumplir con las obligaciones tributarias.

Del total de contribuyentes encuestados en la ciudad de Ambato el 52\% menciona estar de acuerdo que el costo de un sistema de facturación tradicional es elevado, un $31 \%$ afirma estar totalmente de acuerdo, 10\% difiere con la indecisión de la interrogante planteada, un $5 \%$ asegura estar totalmente en desacuerdo con el costo elevado del sistema de facturación tradicional y un $2 \%$ menciona estar 
en desacuerdo. Los costos generados por poseer un sistema de facturación tradicional con documentos impresos son más altos, así como la implementación de un sistema de facturación electrónica, con la diferencia que el sistema de facturación tradicional es considerado como gastos relacionados con el giro del negocio y la implementación de un sistema, es una inversión esencial para la entidad económica. Además del empleo de recursos económicos, se toma en cuenta la reducción de recursos humanos, gracias a la optimización del tiempo.

Sobre la satisfacción del sistema de facturación las respuestas fueron las siguientes: del total de encuestados el $55 \%$ se siente satisfecho con los resultados que les brinda o brindó el sistema de facturación tradicional, el 24\% mencionó estar totalmente de acuerdo, 14\% afirma su desacuerdo con la satisfacción del sistema y un 7\% afirma su insatisfacción hacia la interrogante planteada. En su gran mayoría los contribuyentes encuestados afirman en su momento haber estado satisfechos con el proceso de facturación electrónica, porque era un método conocido y que les brindaba confianza para el manejo de sus operaciones, adicionalmente, un punto importante que destacar es que todos y cada uno de sus clientes se sentían a gusto con efectuar sus compras y recibir un respaldo de las transacciones de manera oportuna, a esto se hace referencia aquellas empresas, donde sus productos están encaminados a un sector específico de clientes de una edad avanzada donde muchos no cuentan con un correo electrónico, y únicamente desean comprar y que su documento los respalde de manera física, cierto grupo minoritario hace notar su insatisfacción hacia el sistema de facturación tradicional por motivos de optimización de tiempo y recursos pues afirman, que el utilizar tecnología dentro del sistema de facturación facilita notablemente el proceso como tal.

Al consultar sobre el empleo de documentos impresos además de digitales se determinó que en su mayoría con un $86 \%$ de contribuyentes encuestados usa frecuentemente documentos impresos además de tener ya su información digitalizada, un $10 \%$ realiza esta acción ocasionalmente, un $2 \%$ raramente y el otro $2 \%$ nunca ha imprimido documentos, únicamente utiliza la información digital. Para la interpretación de esta pregunta los resultados se encuentran bastante marcados pues 36 empresas de un total de 42, aseguran utilizar documentos impresos además, de su registro digital o electrónico, el motivo por el cual se genera este hecho, es que los contribuyentes sienten mayor seguridad al tener un archivo físico que respalde tanto sus compras como sus ventas, es donde se difiere una gran interrogante, existe realmente un ahorro de recursos, o procesos, o simplemente se está duplicando una acción que se llevaba a cabo, con el sistema de facturación tradicional, debido a que el objetivo de la digitalización del sistema de facturación, esencialmente del control tributario que ejerce sobre los contribuyentes, tiene como objetivo la disminución de procesos y fácil comprensión de la mismas, además de generar un ahorro en papelería, y optimización de tiempo en los procesos contables, el porcentaje de empresas que no llevan un registro con documentos impresos es muy pequeño, y aseguran que únicamente el registro digital es esencial para sus empresas. Los documentos que se imprimen con frecuencia son las facturas en su mayoría o totalidad, notas de crédito y guías de remisión. Una realidad de 
la facturación electrónica es que no ha sustituido la impresión de documentos físicos ya que si no es la factura la cual se imprime, siempre existirá un documento soporte que respalde la transacción, aunque el mismo no refleje sustento tributario.

En la digitalización de documentos en el proceso de facturación un 43\% asegura estar totalmente de acuerdo con que la digitalización de los documentos de facturación porque facilita el proceso, el 38\% está de acuerdo con la antes mencionada interrogante, un $17 \%$ se encuentra indeciso, y un $2 \%$ como minoría está en desacuerdo con la pregunta planteada. La digitalización dentro de nuestra población fue aceptada de manera positiva en más de la mitad de encuestados, porque aseguran que con este proceso es mucho más fácil el manejo de la información, así como el manejo de las bases de datos y demás procesos, un claro ejemplo es que muchos de los sistemas de facturación utilizados en estas empresas cuentan con la opción de estar conectados al registro de bases de datos del registro civil, donde únicamente se necesita el número de cedula del cliente, y se encuentra a su disposición toda la información del mismo, otras de las ventajas de tener la información digitalizada es que facilita el control de los registros contables porque en cualquier momento se puede generar un reporte donde se puede apreciar la realidad de la empresa de manera inmediata y con información confiable, una parte de la población se encuentra indecisa sobre la digitalización de los documentos, en los procesos de facturación este grupo se enfoca en la modernización de los sistemas, ya que muchas veces al manejar durante varios años un sistema tradicional, al igual que su personal y la edad del mismo la modernización de su sistema de facturación juega en contra de sus recursos humanos, porque muchos de los responsables de ventas no se sienten a gusto al digitalizar la información, esta realidad constituye para una minoría de empresas que es importante detallar y tomar en cuenta.

Al momento de consultar si su empresa cuenta con un sistema de facturación electrónica indicaron que el $81 \%$ tiene dentro de sus organizaciones un sistema de facturación electrónica, y el 19\% restante utiliza otro tipo de facturación adicional al antes mencionado. Del total de empresas encuestadas 34 cuentan con un sistema de facturación electrónica, los sistemas más utilizados dentro de estas empresas son los software contables, propios de la empresa, los mismos que fueron adaptados para facturar electrónicamente porque en sus inicios se realizaba el mismo proceso pero de manera digital únicamente, entre los sistemas de facturación electrónica proporcionados por los contribuyentes podemos detallar el programa MI NEGOCIO, SISTE ITSA, NIGISU, SWISS SYSTEM, entre otros.

Según el criterio de los contribuyentes encuestados un 36\% está de acuerdo que la implementación de un sistema de facturación es accesible para todos los contribuyentes, un 33\% está totalmente de acuerdo, un 19\% está indeciso en la interrogante planteada un $10 \%$ menciona estar en desacuerdo y finalmente un $2 \%$ está totalmente en desacuerdo. La mayor parte de encuestados aseguran que la implementación de un sistema de facturación es accesible para todos los contribuyentes, viendo desde el punto que son empresas grandes que tienen 
sucursales a nivel nacional, y sus ingresos mismos hacen que la implementación de un sistema de facturación no se refleje como un gasto, sino más bien como una inversión, vital y necesaria dentro de la empresa, si analizamos la realidad de contribuyentes más pequeños, se puede apreciar la respuesta negativa de los encuestados al ser medianamente 0 pequeñas, el costo de implementar un sistema sofisticado es elevado y la inversión se considera de alto riesgo, cosa que no sucede dentro de grandes empresas, donde su flujo de ventas e ingresos representan utilidades que apoyan a la implementación de tecnología y demás requerimientos que la empresa amerite.

\section{DISCUSIÓN DE RESULTADOS}

La capacidad de respuesta de los contribuyentes frente a las resoluciones emitidas por la administración tributaria, es satisfactoria, pues se ve una conducta de cumplimiento con el fin de evitar posibles sanciones, en su mayoría los contribuyentes ven el beneficio que se obtiene con la digitalización de la información financiera, pero en ciertos casos la inmersión de la tecnología, genera temor debido al desconocimiento propio del sistema, para aquellos grandes contribuyentes es de fácil acceso la adquisición de un sistema de facturación que se adapte a las necesidades de su empresa, sin embargo para contribuyentes con un flujo de ventas menor, se ve como un desafío considerando que un software contable requiere de una inversión considerable, por esta razón, el servicio de rentas internas ha generado un sistema eficiente y de fácil comprensión donde se pueda facturar de manera electrónica, y, este servicio, está dedicado exclusivamente a aquellos pequeños contribuyentes, que posteriormente se muestren en la obligatoriedad de facturar de forma electrónica.

\section{CONCLUSIONES}

El sistema de facturación se vio inmerso en un sin número de cambios, los mismos que fueron a causa de la implementación del sistema de facturación electrónica, donde la digitalización de los documentos facilitó de gran manera el control y adecuado registro contable.

Mediante la adopción de los diferentes sistemas de facturación (sistema tradicional, digitalizado o electrónico) el fin que se busca con las respectivas reformas tributarias al régimen de facturación esencialmente expuesto dentro del reglamento de comprobantes de venta, comprobantes de retención y documentos complementarios, es generar dentro de los contribuyentes las debidas facilidades, no solo desde el punto de vista de la administración tributaria ejercer un mayor control sobre las operaciones económicas de los contribuyentes, sino más bien, poder ver un beneficio directo para los sujetos pasivos del tributo, como finalidad de obtener una información adecuada, debidamente registrada, y generar seguridad sobre su medio de trabajo. 
El sistema de facturación electrónica cumple con las expectativas y requerimientos empresariales, esencialmente al momento de optimizar recursos, como el tiempo y los rubros monetarios. La adquisición de un sistema de facturación sofisticado para grandes empresas es accesible debido a los montos de ventas que se maneja dentro de estas empresas debido a que se lo hace bajo la figura de inversión. Para el caso de medianos y pequeños contribuyentes la implementación de un sistema de facturación electrónica se convierte en un gasto elevado. Algunas entidades con óptimo estado económico han incurrido como un gasto la implementación del mencionado sistema, pues bien, sus operaciones se han manejado eficientemente a lo largo de los años a través de un software contable propio de cada institución, y al requerir facturar de manera electrónica, necesariamente utilizan un sistema adicional y exclusivo para su facturación.

El principio de simplicidad administrativa se ha cumplido mediante la evolución del sistema de facturación en conjunto con la normativa tributaria, porque ha permitido que los procesos disminuyan notablemente en el ámbito de la facturación, gracias a la automatización de los diferentes sistemas electrónicos para facturar, permitiendo reducir el papeleo en una gran proporción. Este principio determina la obligatoriedad que tiene la administración tributaria al brindar al contribuyente las facilidades necesarias al momento de pagar sus obligaciones tributarias, simplificación en los procesos, esto permite que se cumpla con este principio generando un adecuado y oportuno cumplimiento de sus obligaciones tributarias.

Es un factor clave conocer sobre los principios tributarios que representan el cumplimiento de los derechos que tienen los contribuyentes y su finalidad es generar un soporte y confianza para que una reforma a la normativa sea en beneficio primordial de estos y colateralmente de la administración quien a través de sus resoluciones busca mejorar y facilitar el cumplimiento de dichas obligaciones. Los incentivos tributarios deben verse reflejados para aquellas circunstancias que lo ameritan, más no para el cumplimiento que son propios de los contribuyentes, si bien se exige que se cumplan a cabalidad y de manera equitativa los derechos que corresponden a las entidades de la misma manera se debe cumplir los deberes que están impuestos por la normativa tributaria.

La aplicación del principio de simplicidad administrativa se ve reflejado en el cumplimiento de los objetivos de las sociedades estudiadas, pues se considera que con la adopción de la normativa vigente, en relación al sistema de facturación, facilita el cumplimiento de sus obligaciones tributarias, las mismas que se cumplen de manera sencilla, pues sus transacciones (compras y ventas) se mantienen actualizadas constantemente, a través de la utilización de medios electrónicos que facilitan y disminuyen los procesos dentro de la vida económica de los contribuyentes, los mismos que se ven reflejados en el control y optimización que realiza la administración tributaria. 


\section{REFERENCIAS}

ALCALÁ, A. (1846). Historia de España. Madrid: Imprenta de la sociedad literaria y tipo gráfica.

ANALUISA, V. (23 de 08 de 2011). Consultoría Jurídica Abogados de Loja. Obtenido de https://vicenteanaluisa.wordpress.com/2011/03/29/ principios-del-derecho-tributario/

AZPIAZU, J. A. (1820). El comercio según Foronda. España: Pirineos.

BARBERÁN, M., \& UNAPANTA, J. (2016). ANÁLISIS DE LA COMPOSICIÓN Y LOS RIESGOS DEL SISTEMA FISCAL ECUATORIANO. Quito: UDLA.

BUSTOS, J. (2007). El impuesto al valor agregado y el régimen de facturación . Quito: Cevallos editora jurídica.

BUSTOS, J. (2012). Tributarium. Obtenido de http://tributarium.blogspot. com/2012/03/agua-y-aceite-la-simplicidad.html

GONZÁLEZ, C. (2012). LA FACTURACIÓN ELECTRÓNICA COMO EVOLUCIÓN DE LA FACTURA TRADICIONAL. México: CUAUTITLÁN IZCALLI, EDO. DE MÉXICO.

GONZÁLEZ, D. (2006). REGIMENES ESPECIALES DE TRIBUTACIÓN PARA PEQUEÑOS. Diálogo Internacional de Fiscalidad, 57.

REVELLES, G. (2017). KeyANDCloud. Obtenido de https://www.keyandcloud. com/la-historia-la-factura/

ROMERO, M., \& FAJARDO , C. (2010). Aspectos jurídicos y tributarios de la factura como título de valor. Contabilidad y aspectos tributarios, 24.

SOLANO, L. (2004). SALA CONSTITUCIONAL DE LA CORTE SUPREMA DE JUSTICIA. Quito.

TORRES, T. (2012). Diccionario de Derecho Tributario. Quito: Editorial Corporación de Estudios y Publicaciones CEP.

ZAMBRANO, A. (2010). Derecho Tributario. Obtenido de http://alexzambrano. webnode.es/products/principios-del-derecho-tributario1/ 